\title{
Comparison between intravenous iron sucrose versus oral iron therapy in pregnant women with nutritional anemia: a prospective study
}

\author{
Archna Tandon*, Vineeta Gupta, Priyanka Chaudhari, Nidhi Kumari
}

\begin{abstract}
Department of Obstetrics and Gynaecology, Shri Guru Ram Rai Institute of Medical and Health Sciences, Dehradun, Uttarakhand, India
\end{abstract}

Received: 10 May 2016

Revised: 04 June 2016

Accepted: 07 June 2016

\author{
*Correspondence: \\ Dr. Archna Tandon, \\ E-mail: archnatandon_1967@yahoo.co.in
}

Copyright: (c) the author(s), publisher and licensee Medip Academy. This is an open-access article distributed under the terms of the Creative Commons Attribution Non-Commercial License, which permits unrestricted non-commercial use, distribution, and reproduction in any medium, provided the original work is properly cited.

\begin{abstract}
Background: In India, the prevalence of anemia during pregnancy may be as high as $80 \%$. The objective of this study was determining the efficacy of intravenous iron sucrose and oral iron in nutritional anemic antenatal patients, presenting at Shri Guru Ram Rai Institute of Medical and Health Sciences Dehradun, Uttarakhand, India.

Methods: The study was carried out in the department of obstetrics and gynecology, Shri Guru Ram Rai Institute of Medical and Health Sciences, Dehradun, Uttarakhand, India single center study was performed on 400 antenatal patients with nutritional anemia gestational age 14 to 36 weeks. Patients were divided in two groups A and B. Group A was treated with intravenous iron sucrose and group B was treated with oral iron sulfate.

Results: There was significant improvement in the various hematological parameters in IV sucrose group as compared to patients in oral iron group. There were no significant allergic reactions in IV sucrose group.

Conclusions: This study has shown a significant improvement in the iron sucrose group. Iron sucrose is safe and well tolerated.
\end{abstract}

Keywords: Iron sucrose, Anemic antitpartum women, Nutritional and iron deficiency anemia

\section{INTRODUCTION}

In India, the prevalence of anemia during pregnancy may be as high as $80 \%$. Anemia is responsible for $40-60 \%$ of maternal deaths in non-industrialized countries. Nutritional deficiency anemia (isolated or combined iron, folic acid, B12, proteins) is the commonest type of anemia during pregnancy. ${ }^{1}$ Inadequate antenatal care along with poor knowledge of dietary needs of pregnant woman and overall poor socio-economic conditions are all responsible for this in our country.

A large number of pregnant women reach the hospitals from hilly areas of Uttarakhand with moderate to severe anemia and that too, late in pregnancy, when no time is left for oral iron therapy. Injectable iron (iron sucrose complex) is likely to be helpful throughout the course of pregnancy in combating the problem of iron deficiency anemia in these women. Moreover, women who have side effects with oral iron therapy will also be greatly benefited.

Our national policy of treating nutritional anemia in pregnancy with oral iron is facing a major problem due to non-compliance. Continuous research is required to discover an effective, safe and cheap injectable iron preparation, which can be used for oral iron defaulters. Intravenous iron therapy can replace blood transfusion in antenatal period.

The aim of our study was to know the safety profile, efficacy, side effects of injectable iron sucrose therapy and its comparison with oral iron therapy in nutritional anemia. 


\section{METHODS}

The present study was carried out over a period of 2 years between January 2013 to January 2015 in the department of obstetrics and gynecology at SGRR institute of medical and health sciences, Dehradun. Approval of institutional ethics committee was taken before starting the trial. A randomized, prospective, single center study was performed on 400 antenatal patients with nutritional anemia between gestational ages 14 to 36 weeks. Informed consent was taken from each patient explaining the purpose of the study including beneficial effects as well as side effects of the drug. All pregnant patients with $\mathrm{Hb} \leq 8 \mathrm{gm} \%$, serum ferritin concentration $\leq 15 \mathrm{microg} / \mathrm{L}$ and general blood picture showing dimorphic anemia or microcytic hypochromic anemia were included in the study. They were randomized into two groups as follows: group A consisted of 200 women who received parenteral iron therapy. Iron sucrose was given by intravenous injection on alternate day according to the iron deficit calculated for individual patient. $200 \mathrm{mg}$ elemental iron diluted in $100 \mathrm{ml}$ of $0.9 \%$ normal saline infusion was given, initially at 8-12 drops/minutes for 15-30 minutes and patient was monitored for any sign of allergic reaction. Rest of the infusion was given at 40 drops/minute. Total iron sucrose dose to be administered was calculated from the formula: body weight in kilograms $\times($ target haemoglobin i.e 12 gm\%-actual hemoglobin $\times 2.4+500 \mathrm{mg}$. Injection of folic acid and vitamin B12 was given on alternate days to eliminate the influence of such a deficiency on the results.

Group B consisted of 200 women, who received three $200 \mathrm{mg}$ iron sulphate tablets per day containing $60 \mathrm{mg}$ of elemental iron (i.e., a total of $180 \mathrm{mg}$ of elemental iron per day for 4 weeks) along with B complex tablet daily.

Haemoglobin, haematocrit, serum ferritin and general picture were repeated 4 weeks after the last dose of intravenous iron or oral iron. Target $\mathrm{Hb}$ was $12 \mathrm{gm} / \mathrm{dl}$. Clinical improvement was noted. Adverse reactions likely to be linked with the treatment were identified such as tachycardia, fever, arthralgia, abdominal pain, and tightness in the chest, vomiting, headache, vertigo, digestive problems, skin eruptions, allergic reactions and a strange taste during injection.

Statistical analysis was performed using the statistical package for the social sciences. Data values are expressed as mean $\pm \mathrm{SD}$, count ( $\%$ age) and $\mathrm{p}<0.05$ is considered to be statistically significant.

\section{RESULTS}

Table 1: Data of women in IV iron sucrose and oral iron groups.

\begin{tabular}{|c|c|c|c|}
\hline Parameters & Group A & Group B & $P$ value \\
\hline & (IV sucrose) & (Oral iron) & \\
\hline Mean age (years) & $24.1 \pm 5.36$ & $25.8 \pm 5.28$ & NS \\
\hline Mean weight (kg) & $50.5 \pm 3.45$ & $52.9 \pm 2.07$ & NS \\
\hline $\begin{array}{l}\text { Parity (number of } \\
\text { primi /multi) }\end{array}$ & $80 / 120$ & $64 / 136$ & NS \\
\hline Mean & $6.17 \pm 0.47$ & $6.92 \pm 0.59$ & NS \\
\hline \multicolumn{4}{|c|}{ Haemoglobin (gm\%) } \\
\hline Mean ferritin $(\mu \mathrm{g} / \mathrm{l})$ & $9.47 \pm 1.01$ & $10.0 \pm 1.70$ & NS \\
\hline Mean PCV (\%) & $16.8 \pm 1.76$ & $18.6 \pm 1.36$ & NS \\
\hline
\end{tabular}

Table 2: Changes in various hematological parameters.

\begin{tabular}{|lllll|}
\hline Test & & Group A & Group B & P-Value \\
\hline Hb (gm/dl) & & (IV sucrose) & Nral iron) \\
\hline & Baseline & $6.17 \pm 0.47$ & $6.92 \pm 0.59$ & $0.004 \#$ \\
\hline Hematocrit $(\%)$ & Four week & $10.08 \pm 0.66$ & $08.38 \pm 1.05$ & NS \\
\hline & Baseline & $16.8 \pm 1.76$ & $18.6 \pm 1.36$ & $0.004 \#$ \\
\hline & Four week & $46.06 \pm 1.99$ & $33.45 \pm 3.17$ & NS \\
\hline & Baseline & $9.47 \pm 1.01$ & $10.0 \pm 1.70$ & $<0.0001 \#$ \\
\hline & Four week & $285.5 \pm 45.1$ & $162.8 \pm 33.1$ & NS \\
\hline Reticulocyte count $(\%)$ & Baseline & $1.69 \pm 0.14$ & $1.63 \pm 0.16$ & 0.209 \\
\hline & Four week & $4.27 \pm 0.18$ & $4.2 \pm 0.19$ & NS \\
\hline MCHC (gm \%) & Baseline & $25.01 \pm 1.73$ & $24.6 \pm 2.06$ & 0.009 \# \\
\hline & Four week & $34.1 \pm 0.97$ & $32.08 \pm 1.41$ & NS \\
\hline MCV (fl) & Baseline & $70.28 \pm 0.96$ & $70.1 \pm 1.96$ & $<0.0001 \#$ \\
\hline & Four week & $93 \pm 1.13$ & $85.8 \pm 3.97$ & NS \\
\hline Hypochromasia $(\%)$ & Baseline & $47 \pm 3.82$ & $46.6 \pm 1.35$ & $0.001 \#$ \\
\hline & Four week & $2.43 \pm 0.16$ & $2.37 \pm 0.14$ & \\
\hline
\end{tabular}

\# sign indicates statistical significance. 
In our study, 400 pregnant women with Iron deficiency anemia were randomized to receive intravenous iron sucrose (group A) or oral iron (group B) treatment. The two groups were comparable in terms of age, weight, parity, Hb levels, ferritin levels and PCV\% (Table 1). As seen in Table 2, in group A, after 4 weeks, mean rise in Hemoglobin was from $6.17 \pm 0.47$ to $10.08 \pm 0.66$ and rise in ferritin levels was from $9.47 \pm 3.01$ to $285.5 \pm 45.1$ which was statistically significant. In group $B$, mean rise in Hemoglobin was from $6.92 \pm 0.59$ to $8.12 \pm 1.05$ and rise in ferritin levels was from $10.0 \pm 1.70$ to $162.8 \pm 33.1$ which was statistically significant. As seen in Figures 1 and 2, mean increase in $\mathrm{Hb}$ and ferritin levels were more in group A as compared to group B and this difference was statistically significant $(\mathrm{P}$ value $<0.004$ and $\mathrm{P}$ value $<0.0001$ respectively). In group $\mathrm{A}$, there was improvement in all parameters. Mean rise in hematocrit $\%$ was from $16.8 \pm 1.76$ to $46.06 \pm 1.99$, rise in $\mathrm{MCHC}$ (gm\%) was from $25.01 \pm 1.73$ to $34.1 \pm 0.97$, rise in $\mathrm{MCV}$ (fl) was from $70.28 \pm 0.96$ to $93 \pm 1.13$, decease in hypochromasia was from $47 \pm 3.82$ to $2.43 \pm 0.16$.

Table 3: Adverse effects of iron treatment.

\begin{tabular}{|lccll|}
\hline $\begin{array}{l}\text { Adverse } \\
\text { effects }\end{array}$ & $\begin{array}{l}\text { Group A } \\
\text { (IV } \\
\text { sucrose) }\end{array}$ & $\begin{array}{l}\text { Discontin } \\
\text { uation of } \\
\text { drug }\end{array}$ & $\begin{array}{l}\text { Group B } \\
\text { (oral } \\
\text { iron) }\end{array}$ & $\begin{array}{l}\text { Disconti } \\
\text { nuation } \\
\text { of drug }\end{array}$ \\
\hline Nausea & - & - & $8 \%$ & - \\
\hline Headache & - & - & - & - \\
\hline Diarrhoea & - & - & $20 \%$ & $8 \%$ \\
\hline Constipation & - & - & $8 \%$ & - \\
\hline Anaphylaxis & & - & - & - \\
\hline Gastritis & - & - & $13 \%$ & $7 \%$ \\
\hline Fever & $4 \%$ & - & - & - \\
\hline Joint pain & $5 \%$ & - & - & - \\
\hline Altered taste & $10 \%$ & - & $12 \%$ & - \\
\hline $\begin{array}{l}\text { Thrombophl } \\
\text { ebitis }\end{array}$ & $4 \%$ & - & - & - \\
\hline
\end{tabular}

In group B also there was improvement in all parameters. Mean rise in hematocrit $\%$ was from $18.8 \pm 1.76$ to $33.45 \pm 3.17$, rise in $\mathrm{MCHC}(\mathrm{gm} \%)$ was from $24.6 \pm 2.06$ to $32.08 \pm 1.41$, rise in $\mathrm{MCV}$ (fl) was from $70.1 \pm 1.96$ to $85.8 \pm 3.97$, decease in hypochromasia was from $46.6 \pm 1.35$ to $2.37 \pm 0.14$. Improvements in all parameters are seen. Mean improvement in hematocrit, MCHC, MCV and hypochromasia was more in group A than group B and this difference was statistically significant.

There were no serious reactions to intravenous iron sucrose in group A but a few patients had grade I, mild to moderate allergic reactions which settled with an antiallergic drug but did not require discontinuation of the infusion. None of the patients had severe life-threatening reactions. Twenty $(10 \%)$ patients reported a metallic taste and $8(4 \%)$ patients had low-grade fever. No hypotensive or hypertensive responses were seen during or after therapy. Eight (4\%) patients developed thrombophlebitis but no thromboembolic complications were seen. In group $\mathrm{B}$, intractable gastrointestinal adverse events leading to discontinuation of drug was seen in 26 (13\%) patients as seen in Table 3. Adverse effects like constipation, diarrhoea, altered taste, nausea and gastritis were mild in both groups but more prominent in group B.

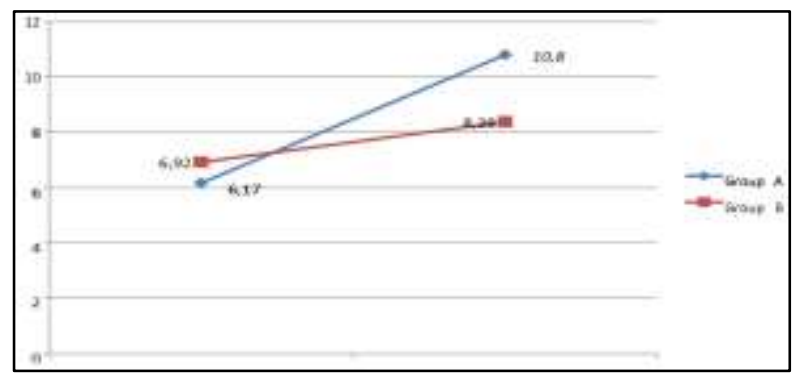

Figure 1: Rise in hemoglobin levels in both groups.

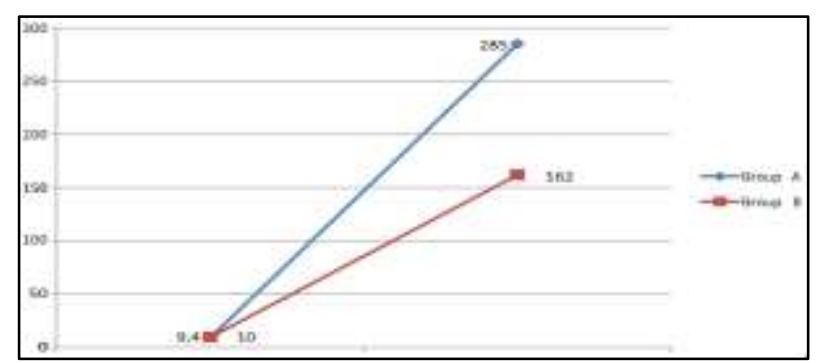

Figure 2: Rise in ferritin levels in both groups.

\section{DISCUSSION}

Nutritional anemia is a major health problem worldwide and specially in developing countries but responds well to iron, multivitamin and protein supplementation. So the clinicians from developing countries should be doing continuous research and should develop their own guidelines to combat such an easy to treat but potentially life- threatening disease.

According to our study, intravenous iron sucrose increases hemoglobin levels and iron stores better than oral iron. A randomized prospective, open study conducted in France by Bayomeu et al involving 50 patients at 6 months of gestation to compare intravenous iron sucrose versus oral route showed an increase in haemoglobin from $9.6 \pm 0.7 \mathrm{~g} / \mathrm{dl}$ to $11.11 \pm 1.3 \mathrm{~g} / \mathrm{dl}$ and $9.7 \pm 0.5 \mathrm{~g} / \mathrm{dL}$ to $11 \pm 1.25 \mathrm{~g} / \mathrm{dL}$ respectively after 4 weeks of treatment $(\mathrm{P}<0.001){ }^{2}$ This is in contrast to our study in which, mean rise in Hemoglobin was from $6.17 \pm 0.47$ to $10.08 \pm 0.66$ in intravenous iron sucrose group and $6.92 \pm 0.59$ to $08.38 \pm 1.05$ in oral iron group .

In a study conducted by A Dede et al IV iron therapy was compared with oral iron therapy. ${ }^{3}$ They found significantly increased serum ferritin level within 28 days with fewer adverse effects than oral iron therapy in women with postpartum iron deficiency anemia. Results of this study showed improvement in ferritin levels but no significant correction in hemoglobin. The reason may be the number of patients taken in their study was less and moreover the base line mean hemoglobin was more than the present study. 
In a study conducted by Wali $\mathrm{A}$ et al at Aga Khan Hospital for women and children Karachi on 60 pregnant women at 12-34 weeks gestation with iron deficiency anaemia. ${ }^{4} \mathrm{I} / \mathrm{V}$ iron sucrose were compared to iron sorbitol. Mean increase of $2.6 \mathrm{~g} / \mathrm{dl} \mathrm{Hb}$ was seen in iron sucrose group within three weeks' time.

The results are comparable to present study. In a study Perewusnyk $\mathrm{G}$ et al used parenteral Fe-sucrose in cases of severe Fe deficiency, anaemia during pregnancy. ${ }^{5}$ They found the fe-sucrose efficient and safe. According to them rate of blood transfusion could be reduced considerably. The results are comparable to the present study.

A similar study conducted by AI RA et al conducted a randomized open study 90 women with $\mathrm{Hb}$ levels between 8 and $10.5 \mathrm{~g} / \mathrm{dl}$ and ferritin values less than 13 microg/L received either oral iron or intra venous iron sucrose. ${ }^{6}$ The change in hemoglobin and ferritin from baseline was significantly higher in the intravenous group than the oral group on day 14 and 28.The results are comparable to the present study

In an open, randomized controlled trial, Westad et al analyzed the effect of IV ferrous sucrose compared with oral ferrous sulphate on hematological parameters and quality of life in women with post-partum anemia. ${ }^{7} \mathrm{~A}$ total of 128 post-partum women with hemorrhagic anemia ( $\mathrm{Hb}$ between $6.5 \mathrm{~g} / 100 \mathrm{ml}$ and $8.5 \mathrm{~g} / 100 \mathrm{ml}$ ) were included in this study. After 4 weeks, the mean $\mathrm{Hb}$ values in both groups were similar $(11.9 \mathrm{~g} / 100 \mathrm{ml}$ versus 12.3 $\mathrm{g} / 100 \mathrm{ml}, \mathrm{p}=0.89)$. The mean serum ferritin value after 4 weeks was significantly higher in the intervention group with $13.7 \mathrm{microg} / \mathrm{L}$ versus $4.2 \mathrm{microg} / \mathrm{L}$ in the control group ( $\mathrm{p}<0.001$ ). At 8 and 12 weeks, the hematological parameters were similar. The total fatigue score was significantly improved in the intervention group at week 4, 8 and 12, whereas SF-36 scores did not differ. The authors concluded that women who received $600 \mathrm{mg}$ IV iron sucrose followed by standard oral iron after 4 weeks, replenished their iron stores more rapidly and had a more favorable development of the fatigue score indicating improved quality of life. The results of above study are showing a rise in ferritin levels but the rise in $\mathrm{Hb}$ levels are not significantly different between the two groups which is not comparable to the present study. The reason may be that they included hemorrhagic anemia in their study.

\section{CONCLUSION}

Intravenous iron therapy is safe, convenient and more effective then oral iron therapy in treatment of iron deficiency anemia and when compliance is the problem and when patients are coming from difficult geographical conditions and approaching the hospital late in pregnancy. Limitations with intravenous iron replacement include the need for medical supervision in the setting of limited healthcare resources.

\section{ACKNOWLEDGEMENT}

Authors would like to acknowledge contribution of department of obstetrics and gynaecology and pathology of Shri Guru Ram Rai Institute of Medical and Health sciences Dehradun, Uttarakhand, India.

\section{Funding: No funding sources}

Conflict of interest: None declared

Ethical approval: The study was approved by the Institutional Ethics Committee

\section{REFERENCES}

1. Sharma JB. Nutritional anaemia during pregnancy in non-industrialized countries: Progress in obstetrics and gynaecology. 2010;23(4):253-60.

2. Bayoumeu F, Subiran-Buisset C, Baka NE, Legagneur H, Monnier-Barbarino P, Laxenaire MC. Iron therapy in iron deficiency anemia in pregnancy: intravenous route versus oral route. American journal of obstetrics and gynecology. 2002:31;186(3):518-22.

3. Dede A, Uygur D, Yilmaz B, Mungan T, Uğur M. Intravenous iron sucrose complex versus oral ferrous sulfate for postpartum iron deficiency anemia. International Journal of Gynecology and Obstetrics. 2005;90(3):238-9.

4. Wali A, Mushtaq A. Comparative study efficacy, safety and compliance of intravenous iron sucrose and intramuscular iron sorbitol in iron deficiency anemia of pregnancy. JPMA. 2002;52(9):392-5.

5. Perewusnyk G, Huch R, Huch A, Breymann C. Parenteral iron therapy in obstetrics: 8 years' experience with iron-sucrose complex. British journal of nutrition. 2002;88(1):3-10.

6. AI RA, Unlubilgin E, Kandermir O, Yalvac S, Cakir L, Haberai A. Intravenous versus oral iron for treatment of anemia in pregnancy: a randomized trial. Obstet Gynecol. 2005;106(6):1335-40.

7. Westad S, Backe B, Salvesen KA, Nakling J, Økland I, Borthen I, et al. A 12-week randomized study comparing intravenous iron sucrose versus oral ferrous sulphate for treatment of postpartum anemia. Acta obstetricia Et gynecologica Scandinavica. 2008;87(9):916-23.

Cite this article as: Tandon A, Gupta V, Chaudhari P, Kumari N. Comparison between intravenous iron sucrose versus oral iron therapy in pregnant women with nutritional anemia: a prospective study. Int J Reprod Contracept Obstet Gynecol 2016;5:2278-81. 